\title{
Investigation of the Impact of Aging Upon the Mechanical Properties of Cocoa Pod Husk
}

\author{
Renique Murray $^{1 *}$, Sanjay Bachu ${ }^{1}$, Cilla Pemberton ${ }^{1)}$, and Robert Birch ${ }^{1)}$ \\ ${ }^{1)}$ Department of Mechanical Engineering, Faculty of Engineering, University of the West Indies, \\ St. Augustine, Trinidad and Tobago \\ ${ }^{*}$ Corresponding author: renique.murray@gmail.com \\ Received: 09 June 2021 / Accepted: 22 August 2021
}

\begin{abstract}
The husk of fresh cocoa pods has traditionally been considered a waste byproduct in the production of chocolate and other related confectionaries. However, in recent times new research has shed light on an increasing number of uses for this material. Of particular interest are applications that utilize the cocoa pod husk $(\mathrm{CPH})$ for its mechanical properties. In most instances, the $\mathrm{CPH}$ raw material is allowed to age for several days before pre-processing or utilization in the intended application. Despite this, the impact of aging on its mechanical properties is an area that has not been well investigated. Consequently, this work seeks to determine the impact of aging upon the mechanical properties of $\mathrm{CPH}$. To investigate this, several $\mathrm{CPH}$ properties were identified and selected for evaluation. These included $\mathrm{CPH}$ tensile strength, $\mathrm{CPH}$ compressive strength, cocoa pod transverse compressive strength, cocoa pod longitudinal compressive strength, $\mathrm{CPH}$ cutting force, cocoa pod cutting force, $\mathrm{CPH}$ hardness, and $\mathrm{CPH}$ colour. These properties were subsequently assessed over an aging period of seven days. The results obtained indicated that most $\mathrm{CPH}$ mechanical properties vary significantly with aging time. Moreover, $\mathrm{CPH}$ colour was found to be strongly related to the mechanical properties of pod longitudinal compressive strength and $\mathrm{CPH}$ hardness, with correlation coefficients of -0.71 and 0.86 respectively. Further, these relationships were found to be strongly linear in nature and regression analyses indicated that up to $83 \%$ of the variation in longitudinal compressive strength can be accounted for by changes in colour, hardness and aging time. These results provide the basis for the potential development of image analysis and computer vision approaches to $\mathrm{CPH}$ sorting and grading.
\end{abstract}

Keywords: cocoa, pod husk, colour, mechanical properties, property estimation, aging

\section{INTRODUCTION}

Theobroma cacao, or cocoa, is perhaps most well-known for its use in the production of chocolate. The seeds of the ripened cocoa fruit are extracted and processed to produce chocolate and other related confectionaries. Cocoa butter is a significant product of the process and is used not only in chocolate making but in the pharmaceutical and cosmetics indus- tries as well. As a consequence, thousands of tons of cocoa are harvested and traded annually and represents a significant contributor to the national GDP of the countries where it is grown.

However, a key by-product of chocolate production is the cocoa pod husk. The cocoa pod husk accounts for approximately $76 \%$ of the pod's mass; thus, each ton of cocoa 
dry beans produced yields ten tons of cocoa pod husk (Chun et al., 2016; Vriesmann \& de Oliveira Petkowicz, 2017). Traditionally, the cocoa pod husk $(\mathrm{CPH})$ was considered a waste product and consequently, resulted in significant amounts of waste for large scale cocoa farmers (Chan \& Choo, 2013). This in turn encouraged the breeding of diseases and attracted unwanted pests (Munongo et al., 2017; Shodehinde \& Adamson, 2017). Thus, the value-added utilization of CPH not only presents an opportunity for greater economic recovery of investments and greater financial gains but also provides a means of addressing several issues related to the disposal of $\mathrm{CPH}$.

Perhaps one of the earlier known uses of $\mathrm{CPH}$ was in agricultural applications, where farmers have been known to utilize $\mathrm{CPH}$ as mulch or compost. In recent times however, much research has been directed towards the investigation of alternative uses for $\mathrm{CPH}$. In keeping with its use as mulch, researchers have investigated the production of compost manure and biochar from $\mathrm{CPH}$. Several researchers have investigated the use of $\mathrm{CPH}$ as a feedstock for animals or for other food related purposes (Shodehinde \& Adamson, 2017; Nortey et al., 2015; Priyangini et al., 2018; Khanahmadi et al., 2015). Beyond this, a growing area of investigation examines the use of $\mathrm{CPH}$ as a renewable energy source or for energy applications. In some instances, the $\mathrm{CPH}$ is used with little to no processing, as in the case of solid biomass applications like pellets or briquettes (Syamsiro et al., 2011; Syamsiro et al., 2012). In others, CPH derived chemicals are used directly as fuels or as facilitating agents in the development of other fuels (Adjin-Tetteh et al., 2018; Khanahmadi et al., 2016; Ofori-Boateng \& Lee, 2013; Rachmat et al., 2018).

Of greater interest is the work that examines the use of $\mathrm{CPH}$ in applications requiring mechanical strength. Adzimah \&
Asiam (2010) reported on the use of CPH in the production of particle board. Daud et al. (2013) investigated the use of CPH in the production of pulp and paper and found that the results were very favourable. More recently, a number of researchers have been examining the use of $\mathrm{CPH}$ in the development of biocomposites and other similar applications. El-Shekeil et al. (2014) have used $\mathrm{CPH}$ in the development of reinforced thermoplastic composite materials. Their investigations indicated that the flexural strength of the composite increased with increasing cocoa pod husk fibre content. Audu \& Mamman (2013) examined the use of $\mathrm{CPH}$ ash as an admixture for concrete. Their results indicated a limited increase in the compressive strength of the concrete, with an increase in $\mathrm{CPH}$ ash addition. Various arrangements and preparation methods for $\mathrm{CPH}$, as a filler for thermoplastic biocomposites have been investigated (Chun et al., 2013a; Chun et al., 2013b). Their works have found various methods for improving the interfacial adhesion between the hydrophilic $\mathrm{CPH}$ filler and the hydrophobic matrix, resulting in improved mechanical strength of the biocomposite.

In all of the aforementioned cases, the mechanical strength of the $\mathrm{CPH}$ is critical to the application. More specifically, in the development of biocomposites the selection of the filler material is crucial, as it imparts its physical and mechanical properties to the resulting biocomposite material (Ul Haque et al., 2019). Accordingly, ensuring optimal mechanical strength of the filler material is critical. Further, due to the general categorization of $\mathrm{CPH}$ as an agricultural waste product, it is often subject to aging. It is common practice among many farmers to dispose of $\mathrm{CPH}$ by stockpiling it in fields, where it is left to degrade naturally (Nortey et al., 2015; Audu \& Mamman, 2013). Additionally, 
many farmers do not extract the beans from the cocoa pod upon picking. Instead, picked pods can remain in heaps for as many as seven to ten days before the beans are extracted (Wood \& Lass, 2001). Thus, the harvested $\mathrm{CPH}$ is generally not fresh but has been aged for several days before its intended use. As a biological material known to degrade on its own, it is expected that aging will have an impact upon its physical properties.

Notwithstanding, the impact of aging on the mechanical properties of different fruits and agro-products is an area that has been receiving attention in recent years, primarily with the intent of assessing produce maturity. Jahangiri et al. (2016) have examined the impact of aging on Viola variety cucumbers and have found that key mechanical properties such as modulus of elasticity and failure stress, decrease with age. It is believed that these effects are due to changes in moisture content with age. Other researchers have conducted similar investigations on different fruits and have reported similar findings (Singh \& Reddy, 2006). However, Chen (2016) has reported that there are other factors such as changes in cell morphology, that can also negatively affect mechanical properties. The impact of moisture content on mechanical properties of agroproducts have been confirmed by other studies (Korkmaz \& Buyuksari, 2019). Seifi \& Alimardani (2010) investigated the impact of moisture content on the mechanical properties of corn kernels. Their findings indicated that there was a general decrease in mechanical strength properties with increases in moisture content; however, rupture energy was found to increase. Thus, the exact impact of moisture content on mechanical properties can vary for different properties.

Aroyeun et al. (2006) and Hinneh et al. (2018) have both examined the impact of storage time on the commercial quality and viability of cocoa pods and of their beans. Aroyeun et al. (2006) reported significant mass losses during storage, which were attributed to moisture content, while Hinneh et al. (2018) reported changes in colour due to senescence. Despite this, the literature has generally been silent regarding the impact of aging upon $\mathrm{CPH}$ mechanical properties. As such, this work seeks to assess key mechanical and physical properties of $\mathrm{CPH}$. It is further examines the impact of aging upon these properties. In so doing, it seeks to determine key trends and relationships that can be used to optimize the selection and use of $\mathrm{CPH}$ for mechanical strength-based applications. Lastly, this work seeks to determine methods for easily assessing or evaluating $\mathrm{CPH}$ strength, as this would be of great significance to farmers and others in differentiating between $\mathrm{CPH}$ stock for use in mechanical applications, as opposed to other uses.

\section{MATERIALS AND METHODS}

For the purposes of this work, five properties were identified for evaluation and study. The first two properties of immediate relevance are the tensile and compressive strengths. These were identified as they are the primary indicators of the CPH's mechanical strength and have generally been recognized by other researchers as key mechanical properties of plant-based materials (Igathinathane et al., 2010; Dauda et al., 2014; Leblicq et al., 2015). The third property identified was cutting force. Cutting force was considered important, since in all cases where $\mathrm{CPH}$ was used it was first cut or ground into smaller pieces. Accordingly, variations in cutting force will influence the amount of input energy required in preparing the $\mathrm{CPH}$ for further use (Murray et al., 2020). The fourth property identified was hardness. This was considered important, as hardness is known to be well 
correlated with tensile strength for most materials and can be more easily assessed than mechanical strength. Lastly, colour was identified as a key property. $\mathrm{CPH}$ is derived from the cocoa fruit and it is well known that fruit colour is an indicator of the fruit's condition. Further, Hinneh et al. (2018) have reported changes in pod colour post-harvest and attributed it to the onset of senescence and possible microbial activity. Thus, it is likely that there may exist a relationship between colour and the strength of the $\mathrm{CPH}$. Further, there may also be relationships between colour and the other physical properties identified. The existence of such relationships could form the basis for image analysis and computer vision approaches, which can be employed to significantly improve the selection and utilization processes. Moreover, it is well known that the impact of moisture content on the mechanical properties of agro-based products is rather significant. However, for the purposes of this work, the property of moisture content was not examined as its relationship with cocoa pod aging has already been explored and established by other researchers. Thus, the authors sought not to reproduce known relationships but instead to leverage them in the analysis of this work's findings. In keeping with this, the impact of aging on the aforementioned properties was examined.

The cocoa pods used in this work, were all obtained from one field managed by the Cocoa Research Centre and located at the University of the West Indies, St. Augustine Campus. All pods were of the same variety, i.e., the Trinitario and were picked based on their average dimensions. The freshly picked cocoa pods were stored in an open container under laboratory conditions of $28^{\circ} \mathrm{C}$ and $1 \mathrm{~atm}$. Further, aging was achieved by storing the cocoa pods under the same conditions for a specified duration. Beyond this, the cocoa pods were not processed or subjected to any additional treatments prior to the testing processes detailed in the subsequent sections.

\section{Tensile and Compressive Strength Tests}

Tensile and compressive strength tests were conducted using a Tinius Olsen $\mathrm{H} 25 \mathrm{KS}$ Universal Testing Machine (UTM). Four distinct tests were done with three samples applied for each test; two of which examined the husk directly and the other two looked at the cocoa pod. More specifically, the four tests conducted were:

- Test 1-Tensile testing of $\mathrm{CPH}$ samples

- Test 2-Compressive testing of CPH samples

- Test 3-Transverse compressive testing of cocoa pod

- Test 4-Longitudinal compressive testing of cocoa pod

For Test 1, cocoa pod husk samples were obtained from freshly picked cocoa by splitting the pods and removing the contents (the cocoa beans). The husks were then manually cut into rectangular samples of dimensions $75 \mathrm{~mm}$ by $27 \mathrm{~mm}$, with an average thickness of $11.5 \mathrm{~mm}$. The sample was placed between the jaws of the UTM, in the manner that is specified for standard tensile tests (Figure 1). In keeping with the rates used by other researchers to represent quasistatic conditions (Igathinathane et al., 2010; Dauda et al., 2014; Leblicq et al., 2015), a strain rate of $10 \mathrm{~mm} /$ minute was selected. The sample then underwent extension until failure and the maximum tensile strength was recorded. The test was conducted for three randomly selected pods and the mean value of tensile strength was determined. The value obtained from these tests represented the tensile strength for freshly picked $\mathrm{CPH}$ and was referred to as the day 0 value. 
Pods that were aged for 24 hours were referred to as day 1 pods. In keeping with this, the procedure described for the day 0 pods was repeated to determine the mean tensile strength for day 1 pods. Further, mean tensile strength values were obtained for day 2 , day 3 , day 4 , day 5 , day 6 and day 7 . The naming convention was commensurate with the duration that the pods were allowed to age for; thus, day 6 values were obtained from pods that were aged for 6 days (144 hours).

In a similar manner to Test 1 , husk samples were prepared for compression testing (Test 2). The average dimensions of the samples used were $51 \mathrm{~mm}$ in length, $15 \mathrm{~mm}$ in width and a thickness of $8.5 \mathrm{~mm}$. The samples were placed between the jaws of the UTM, in a manner that is specified for standard compression tests (Figure 1). The samples were then compressed to approximately 1.5-2 mm thickness, at which point the machine was stopped. The maximum compressive stress value was recorded from the UTM and the mean value was computed from three tests. As with Test 1, mean values were obtained for day 0 to day 7 , using the same aging process previously described.

Tests 3 and 4 were conducted in a similar manner to Test 2. However, unlike Test 2 , a none dissected cocoa pod was mounted in the UTM, as opposed to a CPH sample. For Test 3 the cocoa pod was mounted between the jaws of the UTM, such that the compressive load was applied along the transverse axis as seen in Figure 1. For Test 4, the pod was placed such that the compressive load was applied along the longitudinal axis of

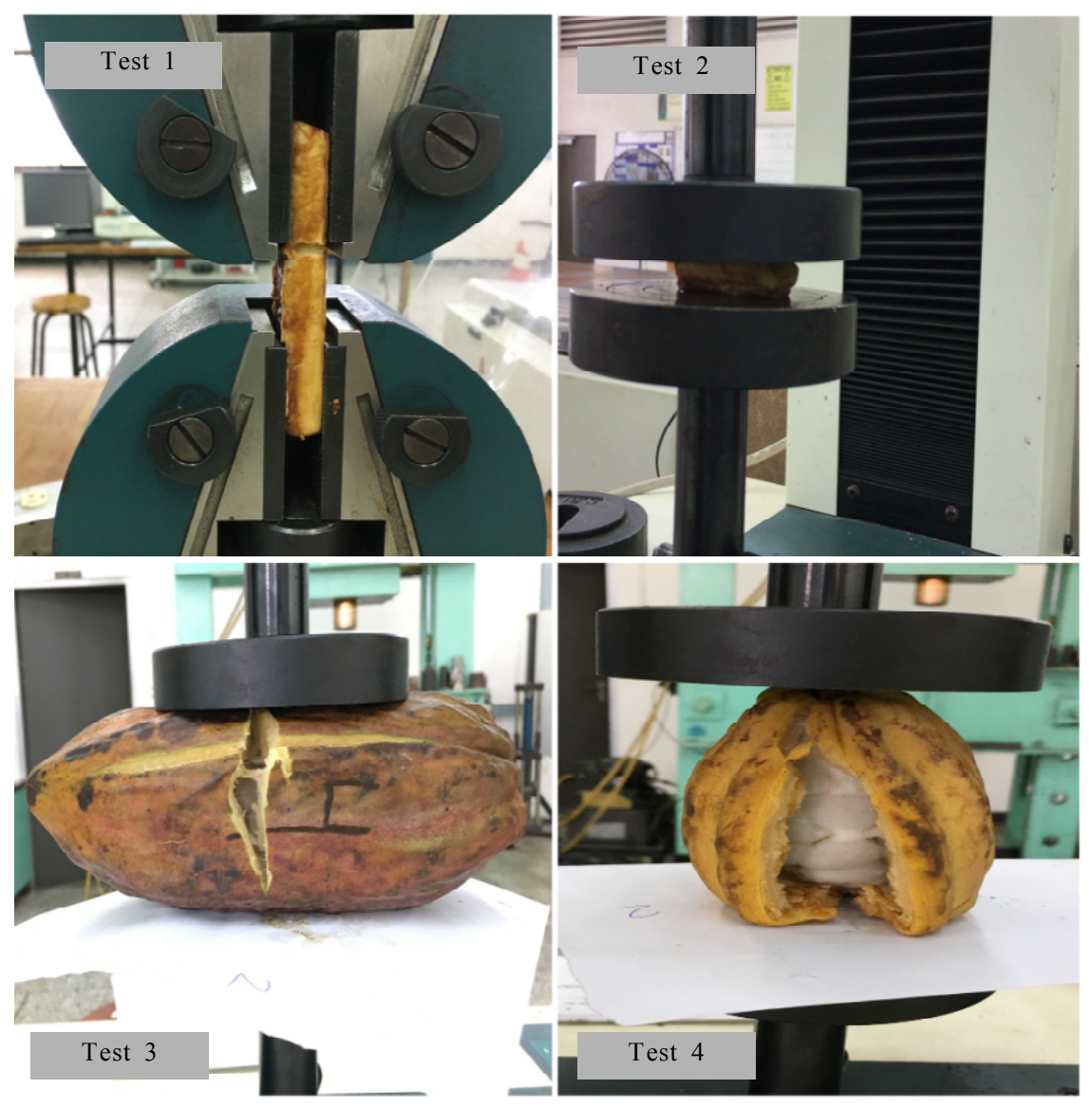

Figure 1. Universal testing machine configuration for tests $1-4$ 
the pod. In both cases, the compressive load was applied until the pod was observed to have a visible failure at some point on its surface. A visible failure was defined as a crack that propagated until physical separation was evident, leaving two distinct separate pieces. As with Test 2, these tests were repeated and mean values were obtained for day 0 to day 7 .

\section{Cutting Force Tests}

The cutting force tests sought to determine the maximum force required to cut the $\mathrm{CPH}$. These tests were conducted using the UTM of Tests 1-4. However, in this instance the UTM was retrofitted to include a cutting blade, as shown in Figures 2a and b. This arrangement allows for the determination of the energy required in separating the husk using pure shear force. Three distinct tests were conducted: Test 5 evaluated the cutting force for a sample of $\mathrm{CPH}$, Test 6 determined the transverse cutting force for an entire pod and Test 7 determined the longitudinal cutting force. For Test 5, rectangular cocoa pod husk samples were manually produced. The samples were of dimensions $26 \mathrm{~mm}$ by 26 $\mathrm{mm}$, with an average thickness of $11 \mathrm{~mm}$. The test speed of the UTM was set to $10 \mathrm{~mm} /$ minute and the test was allowed to proceed until the blade progressed through at least $8 \mathrm{~mm}$ of the sample's thickness. The data was once more recorded by the UTM and presented via a graphical interface. As in the case of the tensile and compressive force tests, these tests were repeated three times to determine a mean value of the cutting force. Further, mean cutting force values were determined for day 0 to day 7 , using the same aging process previously described for the tensile and compressive tests. Tests 6 and 7 were identical to Test 5 , with the exception that whole cocoa pods were used instead of CPH samples. Accordingly, mean cutting force values were obtained for the pods from day 0 to day 7 .

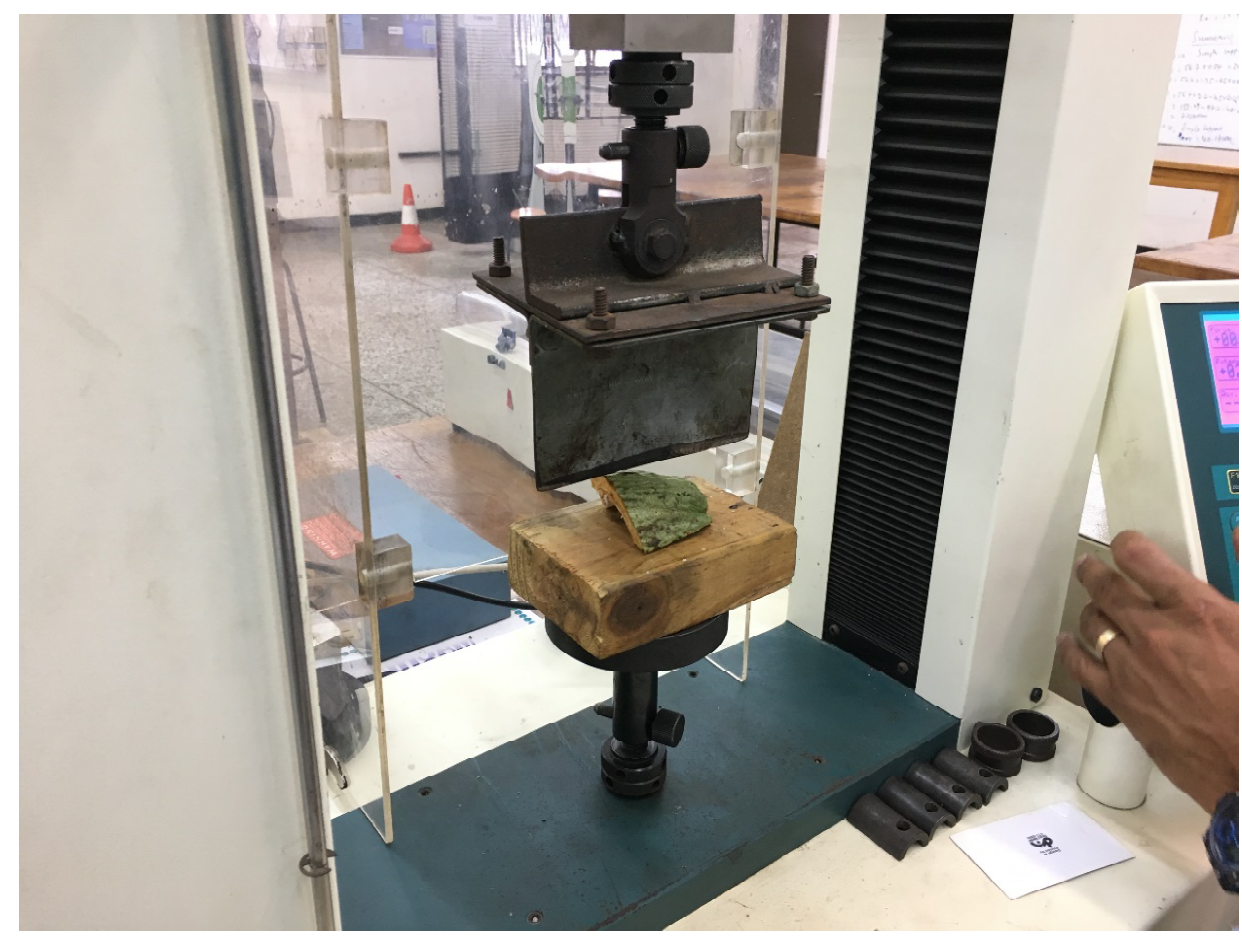

Figure 2a. Universal testing machine configuration for tests 5 


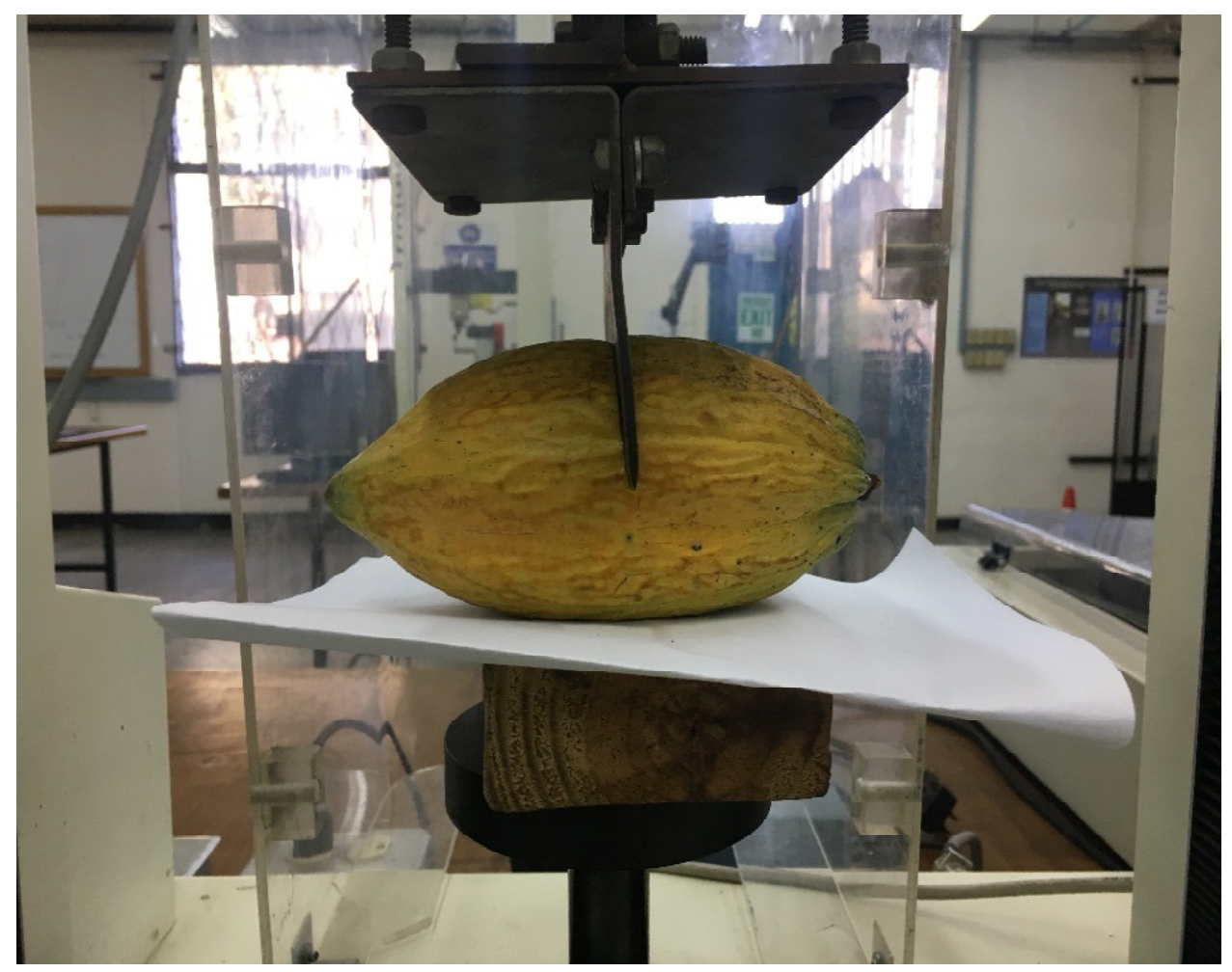

Figure 2b. Universal testing machine configuration for tests 6

\section{Hardness Tests}

Hardness tests were conducted via the use of a penetrometer. For the purposes of this work, a Koehler instrument company model PNR 10 penetrometer was employed. This unit was an electronically activated, gravity type and used a combined added mass and conical tip (a total of $132.5 \mathrm{~g}$ ) for penetration. Whole cocoa pods were mounted onto the penetrometer and the tip was brought down until at rest on the pod's surface (Figure 3). The unit was then activated for a period of 5 seconds and the penetration depth was then recorded. The test was done a total of four times for four separate pods. The sixteen values recorded were then used to determine a mean penetration depth for a pod on a particular day. As with the previous tests, the mean penetration depth was determined for day 0 to day 7 pods, using a similar aging process.

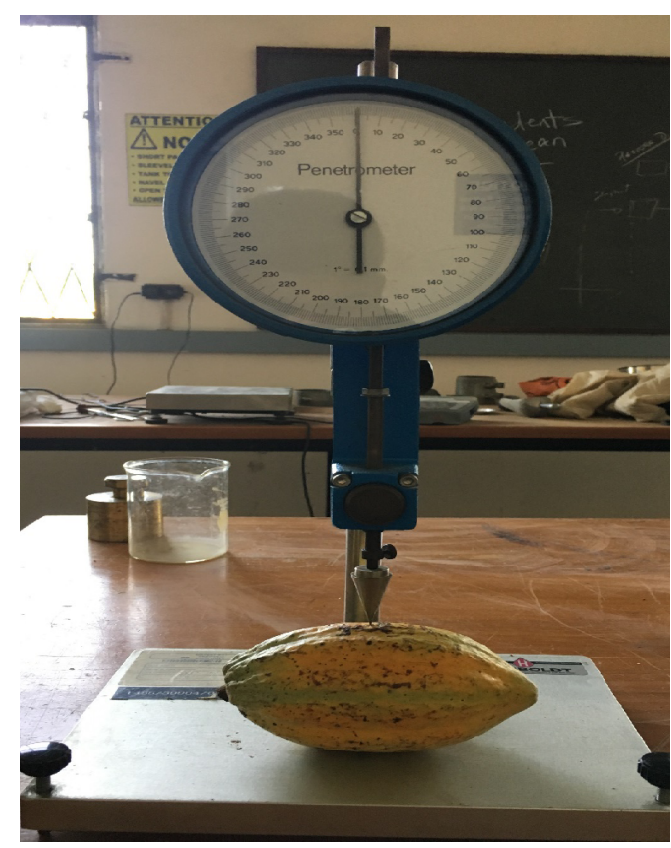

Figure 3. Testing arrangement for test 8-Hardness tests 


\section{Colour Evaluations}

The colour evaluation tests were conducted with the use of a digital camera and the MATLAB software application. A freshly picked cocoa pod was placed on an evenly lit, flat, smooth surface. A digital image of the pod was obtained, with a vertical and horizontal resolution of $72 \mathrm{dpi}$ and $4032 \mathrm{x}$ 3024 pixels. The digital image was subsequently processed using MATLAB 2015's image processing commands, to determine the red, green and blue colour band content of the image. Further commands were used to determine the relative ratios of the three colour bands. This procedure was repeated for three additional freshly picked cocoa pods, with each pod being placed on the same reference surface for the acquisition of the digital image. The results obtained for the four pods were used to determine the mean values of the colour bands and their respective ratios, for the freshly picked or day 0 cocoa pod.

Using the same aging process previously described for the tensile and compressive tests, colour evaluation tests were conducted for pods from day 1 to day 7 . In each case, the procedure was the same as that described for the day 0 pod, using four pods to determine the mean values of the colour bands. Figures $4 \mathrm{a}, 4 \mathrm{~b}$ and $4 \mathrm{c}$ show an example of the images captured for a single pod.

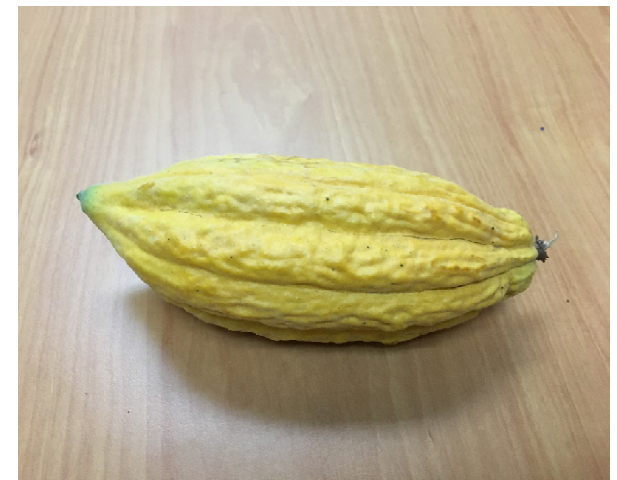

Figure 4a. Photo of a sample pod on day 0

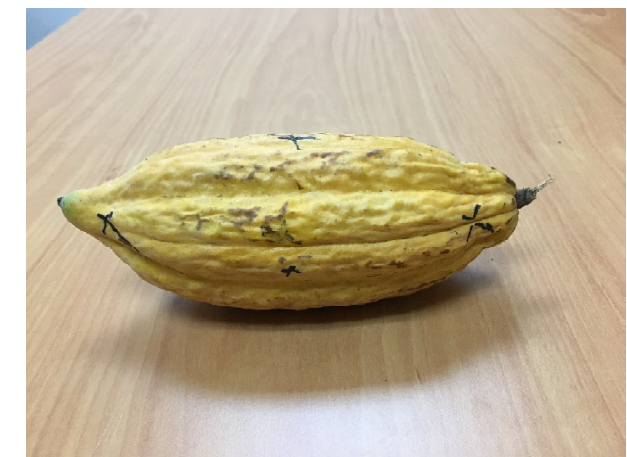

Figure $4 \mathrm{~b}$. Photo of a sample pod on day 3

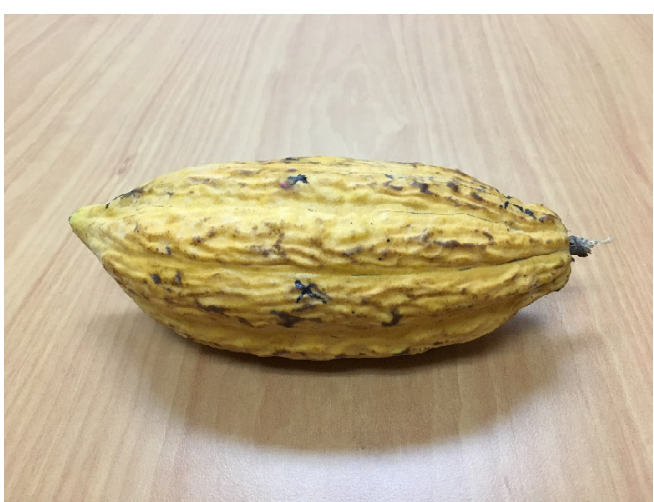

Figure $4 \mathrm{c}$. Photo of a sample pod on day 7

\section{RESULTS AND DISCUSSION}

\section{Tensile and compressive strengths results}

Table 1 shows some mean physical properties for the pods collected over the course of their storage. The data presented was based on four cocoa pod sample measurements per day for each parameter in the table.

The results of Table 1 show the mean values for pod length, diameter, husk thickness and pod mass. It can be seen from the table that the pods obtained ford 3 and 6 record the highest variability. The standard deviation in the mean length on day 3 and 6 , represented a variation of approximately $22 \%$. Similarly, the standard deviation in mean diameter represented a variation of 
approximately $15 \%$. The variation from the mean was generally less than $10 \%$ for other days. Similarly, the maximum variation for the mean husk thickness was found to be approximately $27 \%$ on day 6 and $21 \%$ on day 3 , while it was found to be much lower for other days. Moreover, the variability in pod mass on day 3 and 6 was $49 \%$ and $60 \%$ respectively, while it was generally below $20 \%$ for other days.

These results indicate that there is some degree of variability in the pod's physical parameters. This is somewhat expected, as the Trinitario variety has been known to demonstrate notable variability in the dimensions of pods taken from the same tree (Wood $\&$ Lass, 2001). However, it would be noted that the variations in mass are higher than the variations in length. Though some of this can be attributed to differences in the number of beans within the pods, it is also due to the mass of the pod husk itself. Thus, it is likely that there will be some variation in pod density among the samples. In keeping with this, it is expected that the variability in husk thickness and density among samples will result in some variability in the measured mechanical properties.

Figure 5 shows the results of the tensile tests conducted on the $\mathrm{CPH}$ samples from day 0 to day 7. In general, it can be observed that there is some variation in the measured parameter with aging time. The highest tensile strength was recorded for day 7 samples,

Table 1. Mean and standard deviation data for key physical properties of the cocoa pod samples

\begin{tabular}{lcccc}
\hline Day & Pod thickness $(\mathrm{mm})$ & Diameter $(\mathrm{mm})$ & Length $(\mathrm{mm})$ & Mass $(\mathrm{g})$ \\
\hline 0 & $10.7 \pm 0.43$ & $82.7 \pm 3.06$ & $179.6 \pm 4.93$ & $389.6 \pm 54.4$ \\
1 & $10.9 \pm 1.42$ & $76.3 \pm 1.83$ & $158.1 \pm 12.56$ & $278.9 \pm 19.4$ \\
2 & $12.0 \pm 1.14$ & $88.5 \pm 12.83$ & $171.6 \pm 17.72$ & $353.1 \pm 93.0$ \\
3 & $15.0 \pm 3.31$ & $87.3 \pm 13.5$ & $180.3 \pm 40.01$ & $496.5 \pm 245.8$ \\
4 & $10.8 \pm 1.12$ & $86.2 \pm 5.63$ & $192.1 \pm 20.58$ & $428.1 \pm 84.6$ \\
5 & $11.3 \pm 0.8$ & $80.7 \pm 10.27$ & $197.6 \pm 19.02$ & $383.4 \pm 113.3$ \\
6 & $8.8 \pm 2.4$ & $76.3 \pm 12.76$ & $180.3 \pm 44.55$ & $347.6 \pm 210.5$ \\
7 & $11.4 \pm 1.5$ & $90.6 \pm 10.1$ & $216.5 \pm 16.2$ & $479.5 \pm 88.6$ \\
\hline
\end{tabular}

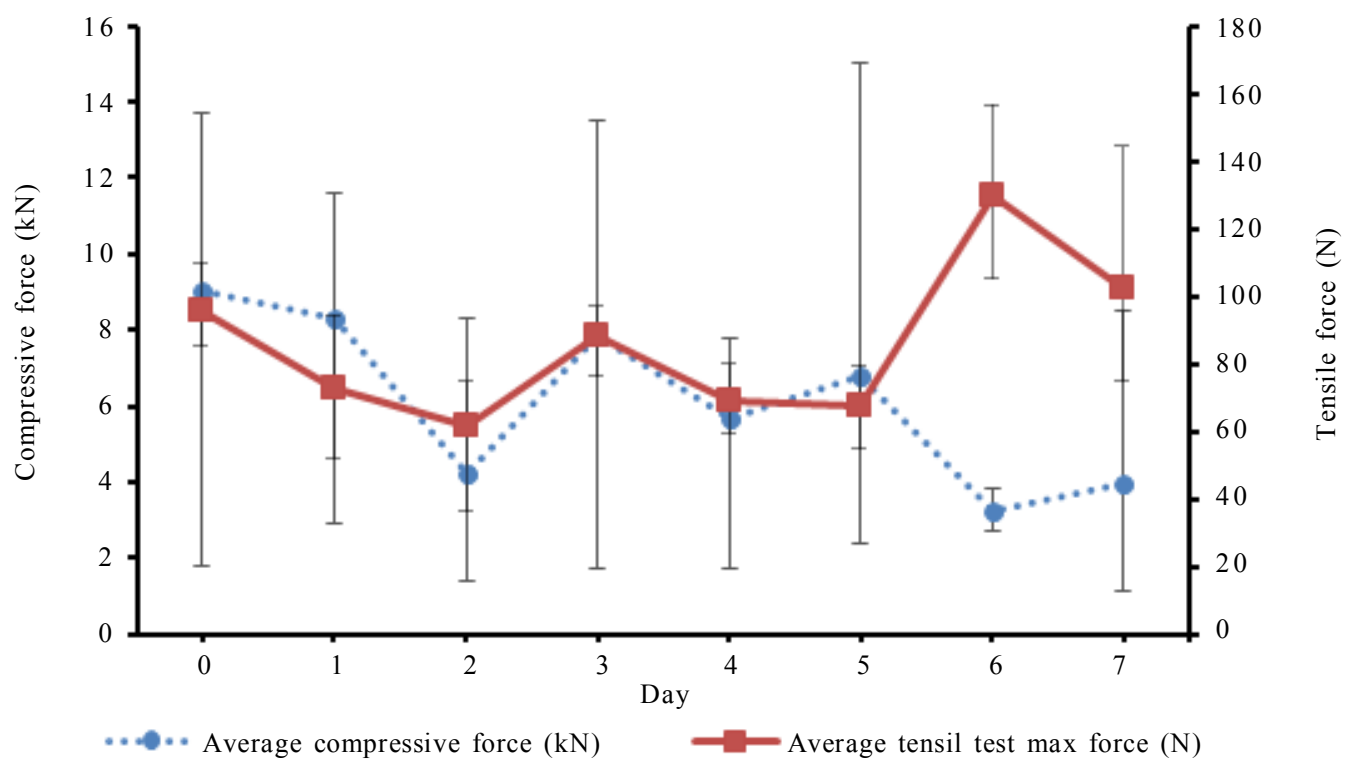

Figure 5. Variation in tensile and compressive force for the $\mathrm{CPH}$ samples over the evaluation period 
with a mean value of $102 \mathrm{~N}$, while the lowest was recorded for day $2(62 \mathrm{~N})$. The data showed little variability in the measured values, with the exception of the day 7 tests, which demonstrated up to a $40 \%$ variability in the measured parameter. In general, it is believed that this variability can be attributed to the inherent variations in Trinitario pods and to the limited number of samples taken for each day.

However, perhaps of greater importance is the impact of aging upon the tensile strength of the samples. Though tensile strength is observed to change with aging time, a definitive relationship between the two parameters is not evident. Further, a correlation analysis of the parameters yields a correlation coefficient of 0.42 (Table 2). This suggests that there is an underlying relationship between the parameters, but that they are weakly related. Notwithstanding this, Figure 5 presents one other characteristic of interest. It can be seen from the figure that tensile strength fluctuates from day 0 to day 5 about an approximate value of $70 \mathrm{~N}$. However, there is a sharp rise in the tensile strength on day 6 . This result may be attributed to changes in the moisture content of the $\mathrm{CPH}$. It has been confirmed by Hinneh et al. (2018) and Aroyeun et al. (2006) that cocoa pods experience a decrease in their moisture content over the duration of storage. More importantly, Aroyeun et al. (2006) reported that over a 24-day examination of cocoa pods in storage under atmospheric conditions, there was a rapid increase in the mass loss due to moisture content after the sixth day. Therefore, it is expected that the pods examined in this work would have also experienced similar decreases in moisture content over the duration of storage. Moreover, given the impact of moisture content on mechanical properties, it is likely that the decreases in moisture content taking place prior to day 6 were not sufficient to enact an appreciable change in the tensile strength. However, from day 6 onwards, the loss in moisture content appears to be sufficient to yield a significant change in the tensile strength of the samples. Thus, this suggests that the property of tensile strength is influenced by moisture content, but also that there is a critical value of moisture content loss that is required before the influence becomes noticeable.

The results of the compressive tests on the $\mathrm{CPH}$ samples are also presented in Figure 5. The figure shows a general decrease in the compressive strength from an average of 9 $\mathrm{kN}$ on day 0 to $3.9 \mathrm{kN}$ on day 7. The relationship between aging time and compressive strength is linear and it suggests that compressive strength decreases with aging. This is further supported by a correlation coefficient of -0.74 (Table 2). A key implication of this, is that in instances where $\mathrm{CPH}$ it to be used for its compressive mechanical properties, fresh $\mathrm{CPH}$ samples will be more effective than aged ones.

However, Figure 5 also shows great variability in the measured parameter. This variability is expected as compressive strength will be significantly affected by husk density and homogeneity and the results of Table 1 suggest variations in these parameters among the samples. Further, this variation may also be partially attributed to the manner in which the tests were conducted. More specifically, given that samples were compressed to an approximate thickness, there was some variation in the point at which the tests were stopped. Accordingly, this would have led to inherent variations in the measured parameter. Nevertheless, it would be noted that the plot of compressive strength appears to show a notable inflection point on day 6 . This is somewhat similar to the plot of tensile strength. It is therefore believed that the decreases in compressive strength are also influenced by losses in moisture content. However, unlike the case of the tensile 
strength parameter, the compressive strength appears to be more responsive to changes in the moisture content.

Figure 6 shows the results of the transverse and longitudinal compressive tests respectively, for whole cocoa pods. In general, the data shows little variability with both tests showing a maximum variability of approximately $40 \%$ for only one of the days. The transverse compressive tests show a general decrease in compressive strength with aging time. A maximum strength of $516 \mathrm{~N}$ was recorded on day 1 , while a minimum of $277 \mathrm{~N}$ was recorded on day 7. The figure shows a general linear relationship between aging time and compressive strength. This is further supported by a correlation coefficient of -0.85 , suggesting that the two parameters are strongly related. This trend is also in keeping with the results obtained for the compression tests of the $\mathrm{CPH}$ samples.
The results obtained for the longitudinal compressive tests follow a similar pattern to those of the transverse tests; the main difference being the magnitudes recorded. In general, the longitudinal compressive strength was higher than the transverse compressive strength, with a maximum of $1019 \mathrm{~N}$ recorded on day 1 and a minimum of $434 \mathrm{~N}$ on day 7 . Similarly, a negative linear relationship was also observed between the longitudinal compressive strength and aging time. A correlation analysis yielded a coefficient of -0.86 , once more indicating a strong relationship between the parameters.

Of particular interest, was the day 6 values for both tests. Figure 6 shows a general decrease in transverse compressive strength from day 0 to day 5 . However, there is a slight increase in the parameter on day 6 . This feature is more pronounced for the plot of longitudinal compressive force. This is similar to the trend observed

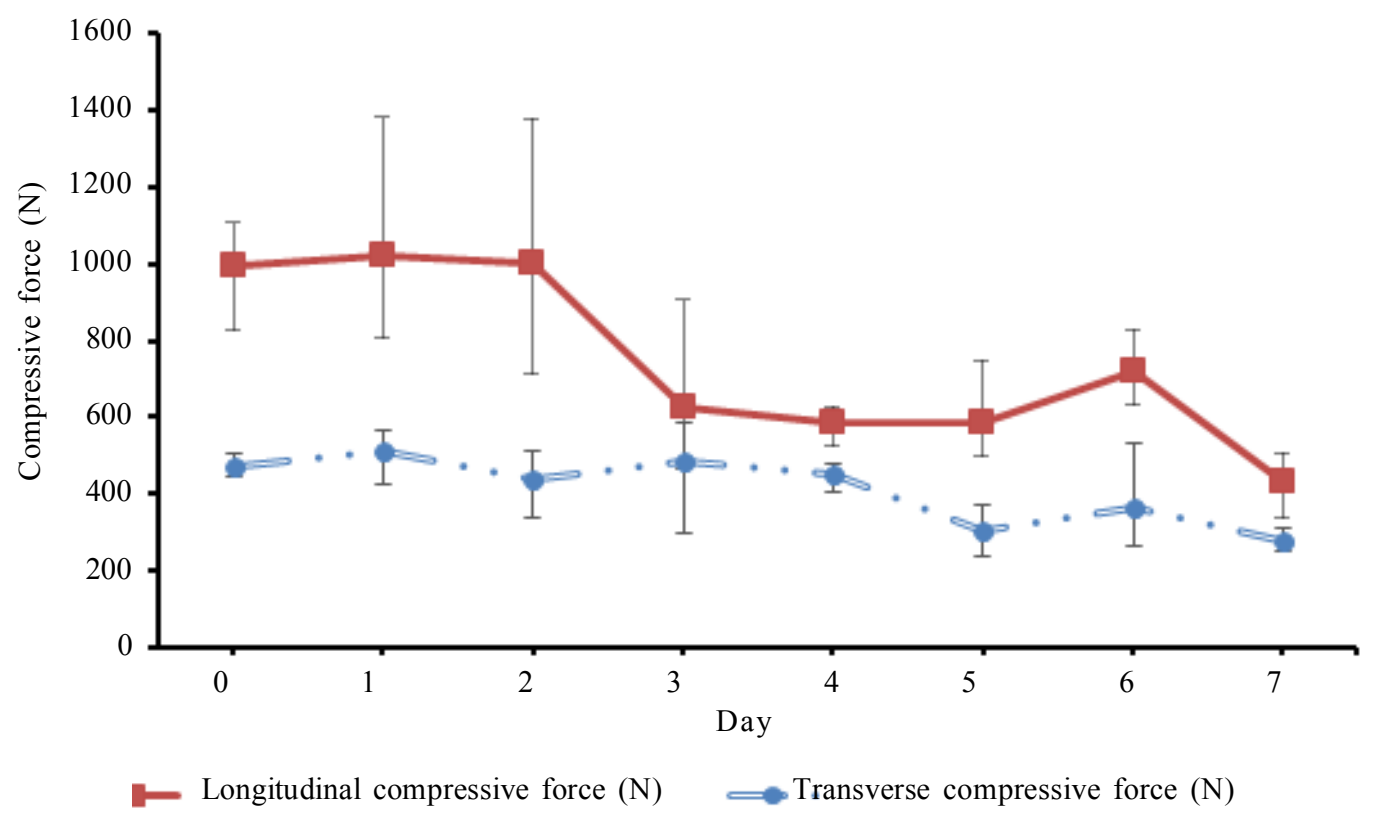

Figure 6. Variation in transverse and longitudinal compressive force over the evaluation period 
for the tensile tests of the $\mathrm{CPH}$ samples and serves to further point to some time-dependent aging mechanisms that affect $\mathrm{CPH}$ 's mechanical properties.

A differentiation was made between tests of CPH samples (Tests 1 and 2) and whole cocoa pods (Tests 3 and 4). The intent was to determine whether the process of dissecting the $\mathrm{CPH}$ would significantly alter its mechanical properties. Accordingly, it was found that the compressive strength of CPH samples was much higher than that of a whole pod. This is an expected result, as the cocoa pod cracks and fails during compression before the husk itself is fully compressed. Accordingly, the compressive strength values obtained from Tests 3 and 4 are lower in value. Beyond this, the general trend of decrease with aging time is evident for both $\mathrm{CPH}$ samples and whole cocoa pods. This indicates that the variation in the underlying mechanical property of strength is essentially the same.
Moreover, considering the results of the three compressive tests, it is believed that the decrease in compressive strength with age is a result of decreasing moisture content. However, the increase in compressive strength on day 6 present for the cocoa pod tests is not seen in the CPH sample tests. The reason for this is unclear, but it is possible that this may be due to other aging related processes taking place within the pod, which may not impact a single dissected sample in the same manner.

\section{Cutting Force Tests Results}

Figure 7 shows the results of the cutting force tests for CPH samples. In general, the results do not show much variability, with the highest variation from the mean being recorded for day 4 and day 7 (approximately $37 \%$ ). From the figure, it can be seen that there is no clearly visible relationship between

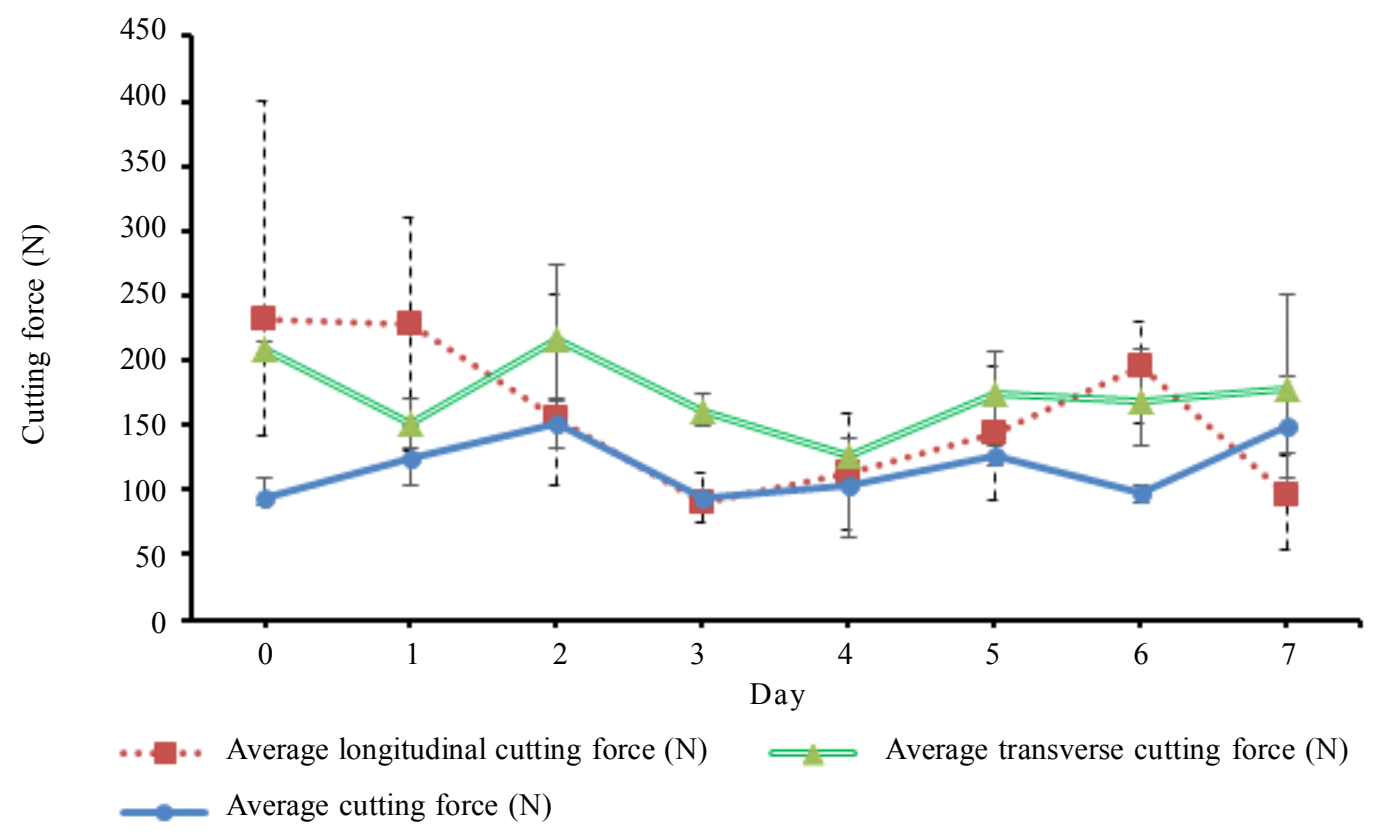

Figure 7. Results of test 5: CPH cutting force 
the aging time and the cutting force. The cutting force appears to fluctuate over the 7-day period, with a maximum of $151 \mathrm{~N}$ on day 2 and a minimum of $94 \mathrm{~N}$ on day 3 . A correlation analysis yields a value of 0.23 , further indicating that there is minimal linear relationship between aging time and cutting force.

The results of the transverse cutting force tests for whole pods, are also shown in Figure 7. The maximum variability in the recorded cutting force is approximately $40 \%$ for the day 7 tests; the remaining tests show little variability in the parameter. Though the magnitudes of the transverse cutting force are higher than those for the $\mathrm{CPH}$ sample cutting force, there seems to be much similarity between the two parameters. Like the $\mathrm{CPH}$ sample cutting force, the plot of the transverse cutting force for whole pods does not show a clear relationship between the cutting force and aging time; the recorded cutting force is seen to randomly fluctuate over the 7-day test period. The lack of relationship between the parameters is further corroborated by a correlation coefficient of -0.28 .

Similarly, Figure 7 also shows the results of the longitudinal cutting force tests. Though the mean values recorded here are rather similar to those of Test 6 , there is a considerable amount of variability in the data, particularly for the first three days. The maximum recorded cutting force occurs on day $0(230 \mathrm{~N})$, while a minimum of $90 \mathrm{~N}$ was recorded on day 3 . A correlation analysis yields a coefficient of -0.58 ; this indicates that there is some level of relationship between the aging time and the longitudinal cutting force, but that there are other influential parameters that have not been accounted for.

A comparison of all three figures yields some useful insights. Firstly, it can be seen that the highest values are recorded for the longitudinal cutting force tests. This suggests that the pod structure is strongest in this orientation. This is further supported by the results of the compressive tests, which also showed that compressive strength was greatest in the longitudinal direction. Of further interest, is the relationship between cutting force and aging time. In general, it can be deduced that aging time has little impact upon cutting force over the duration considered. Accordingly, this implies that the energy input required to reduce $\mathrm{CPH}$ into smaller pieces for use in various mechanical applications, remains essentially unchanged over this period. However, it is likely that as storage time and moisture loss increases, the result on cutting force may become appreciable. Nevertheless, ensuring correct pod orientation during the size reduction process may have an appreciable impact on minimizing machinery energy requirements.

\section{Hardness Tests Results}

The results of the hardness tests are shown in Figure 8. The mean hardness fluctuates across the test period, from a minimum of 0.39 on day 1 to a maximum of 0.66 on day 3 and 0.65 on day 5 . Additionally, there is an average variability in the measured parameter of approximately $40 \%$ for most of the testing period. This variability can be attributed to the factors discussed earlier. Notwithstanding, the figure shows an overarching trend of increase from day 0 to day 5 and a decrease thereafter. This indicates that there is an underlying relationship between pod hardness and aging time and suggests that moisture content is a key factor. However, the exact nature of this relationship is unclear, as evidenced by a correlation coefficient of 0.51 . Once more, this suggests that other aging factors may be of significance. 


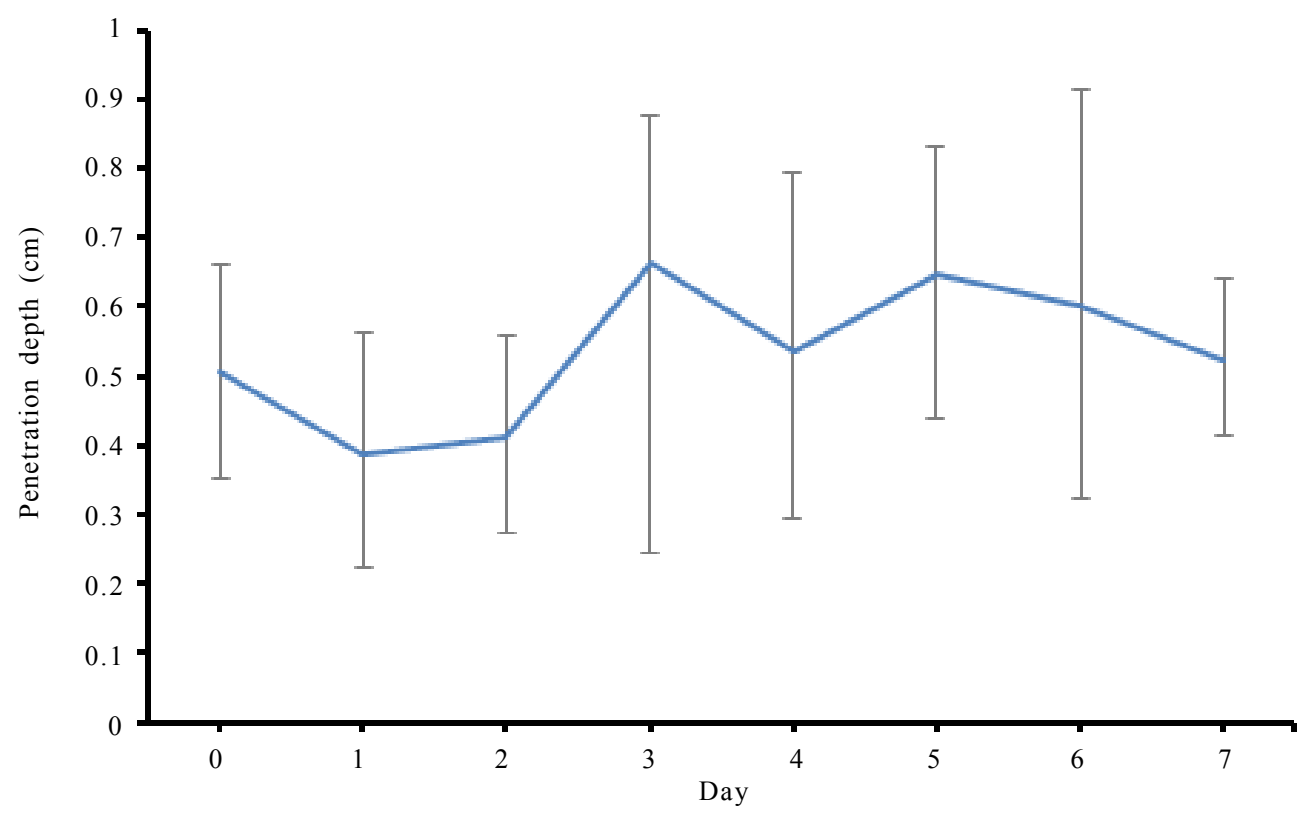

Figure 8. Results of hardness tests

\section{Colour Tests Results}

Figure 9 shows the plots of mean colour band content for the red, green and blue bands over the test period. Immediately evident from the figure is the difference in magnitude between the three bands. The red band consistently has the highest content over the entire period, while the blue band has the lowest. This can be attributed to the general yellowish-orange colour of the cocoa pod, which would contribute significantly to the red colour band. Conversely, the absence of colours within the blue wavelength of the colour spectrum leads to lower content values for the blue band. In general, all three follow a similar pattern, with an increase in colour content magnitude from day 0 to day 4 and a fluctuation thereafter.

The cocoa pods tested in this work are known to be green in colour in the earlier stages of development and become yellowishorange as the pod ripens. Accordingly, the ratio of the red colour band to the green colour band content is of particular interest. Figure 10 illustrates this trend. From the figure, it can be clearly seen that the red/green colour content ratio increases from day 0 to day 5 and then decreases slightly up to day 7 . This suggests that there is a strong relationship between aging time and the red/green colour ratio. More specifically, it suggests that the red colour band content increases more rapidly than the green colour band content, with a commensurate increase in aging time. This is expected based on the known pod ripening characteristics and is further supported by a correlation coefficient of 0.68 .

\section{Key Property Relationships}

The results of the previous sections show the impact of aging time upon different $\mathrm{CPH}$ properties, within the first week of picking. With the exception of cutting force, the $\mathrm{CPH}$ mechanical properties and 


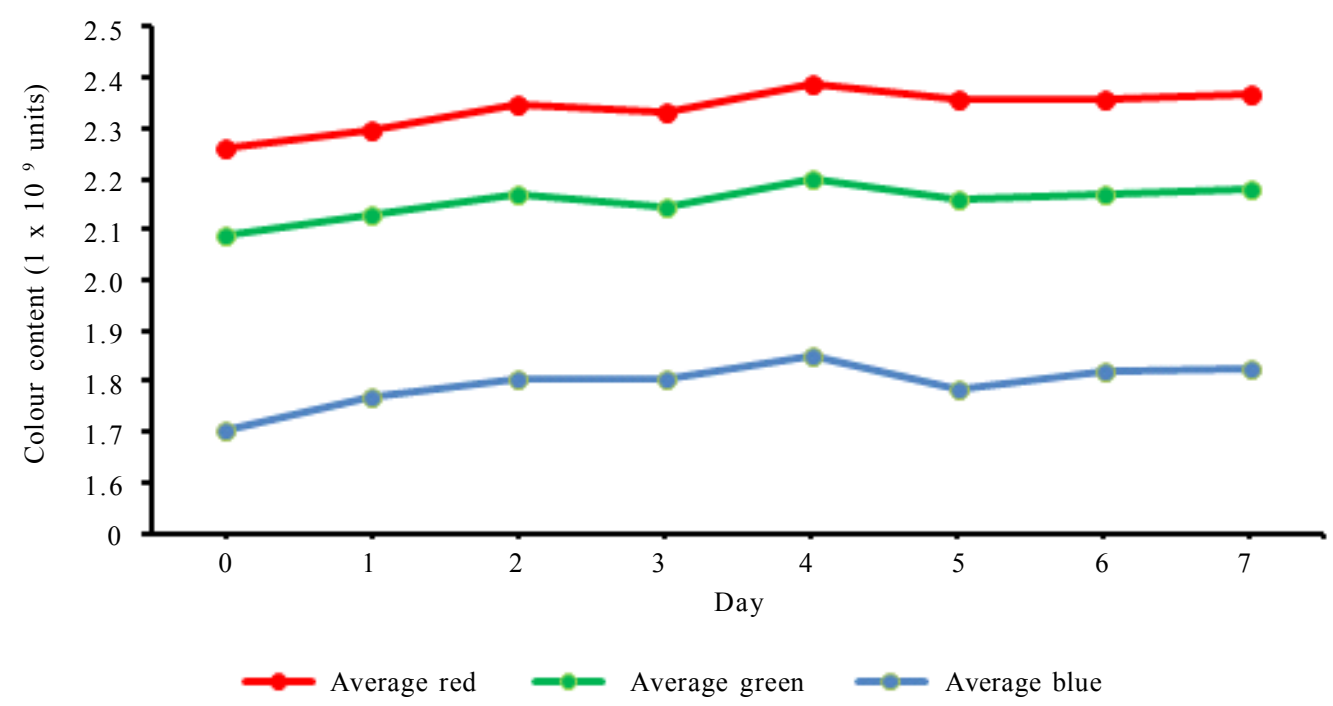

Figure 9. Variation in mean colour band content over testing period

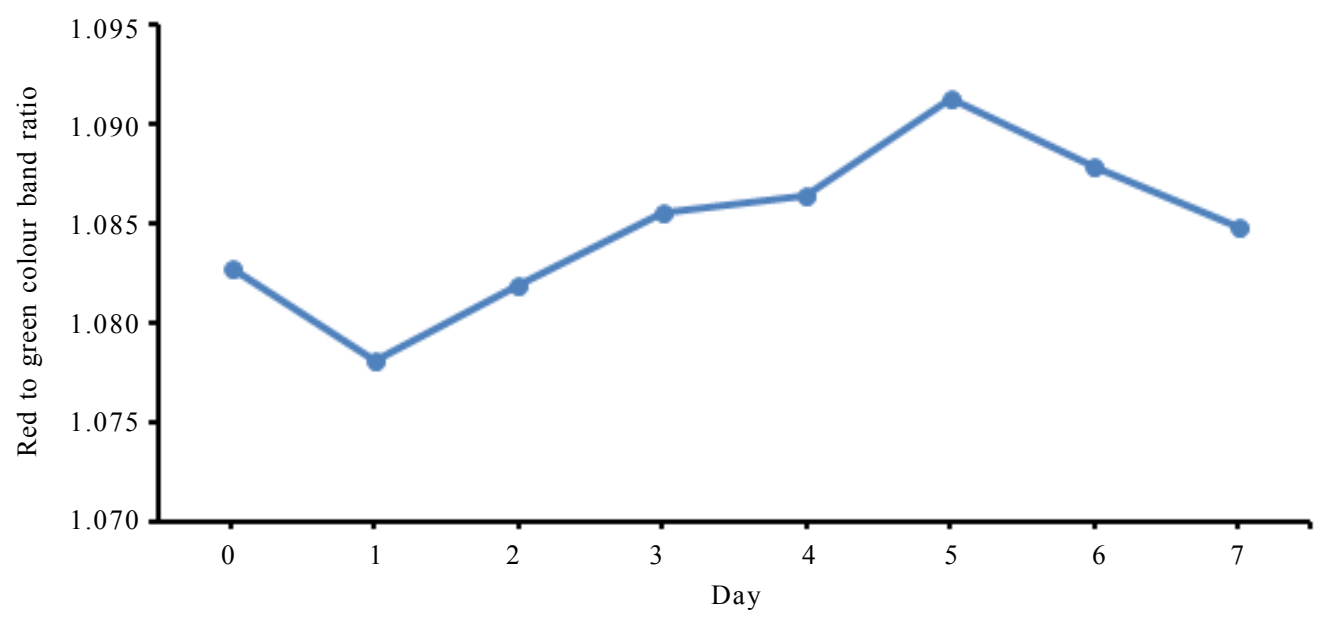

Figure 10. Variation in red/green colour content ratio over testing period

colour were found to be significantly influenced by aging time. Further, it was found that the graphical presentations of the relationships between aging time and these properties, generally indicated a notable change in the value of the property around day 5 or day 6 . The reoccurrence of this phenomenon in most of the mechanical properties points to its significance. As such, it should be noted that the maximum or minimum values of a particular property may occur before or after day 5/6. Consequently, the selection of $\mathrm{CPH}$ for mechanical applications should be guided by this. Moreover, this phenomenon was observed for the changes in colour content as well. This further points to its existence, but perhaps more importantly, points to the possible relationship between colour and the mechanical properties. 
Given the previous findings, statistical correlation analyses were conducted to determine the existence of linear relationships between the mechanical properties and colour, or between the properties and aging time. The analyses were conducted using eight observations for each property and with a significance level of $5 \%$. Table 2 presents a summary of the results. It would be noted that the mean hardness penetration depth and the mean longitudinal compressive strength both show strong correlations with the colour ratio. Further, it would be noted that both are found to be statistically significant. This establishes the presence of a relationship between an external property of the $\mathrm{CPH}$ (its colour) and its mechanical properties. Accordingly, changes in the $\mathrm{CPH}$ colour can be used to assess and/or track changes in the stated mechanical properties.

\section{Property Estimation}

As previously indicated, the values of the Pearson correlation coefficients obtained for these properties further suggest that there is a strong linear relationship between some of the aforementioned parameters and aging time. Consequently, this also forms the basis for the development of a linear relationship for estimating the change in property with aging time. A property estimation equation potentially provides an objective method for assessing the aforementioned properties, in instances where access to the relevant measuring equipment is not available. Moreover, these equations can be easily manipulated and can further be implemented in various approaches and evaluation methodologies. Accordingly, a property estimation equation can form the basis for computerbased approaches, which can potentially increase the ease, speed and reliability of $\mathrm{CPH}$ processing.

In keeping with this, regression analyses were conducted to develop linear estimate equations for each parameter as a function of aging time or as a function of colour ratio. Further, ANOVA analyses using a $95 \%$ confidence interval, indicated that the coefficients for the linear equations were only statistically significant for three equations. These were the equations relating longitudinal compressive strength to aging time, longitudinal compressive strength to colour ratio and hardness to colour ratio. However, given that hardness is often a proxy for mechanical strength, greater attention was directed to the first two relationships. Thus, given the results in Tables 2, the parameter estimate equations are given by Equations 1 and 2:

Compressive Strength $=$

$-80.4(\mathrm{t})+1027.2$

Where $t$ is aging time in days, and

Compressive Strength $=$

$-41117.6(\mathrm{r} \mid \mathrm{g})+45350.6$

Where $\mathrm{r} \mid \mathrm{g}$ is the red/green colour ratio.

Table 2. Correlation coefficients between various $\mathrm{CPH}$ properties and aging time

\begin{tabular}{lcrrr}
\hline \multirow{2}{*}{ Property 1 } & \multicolumn{2}{c}{ Aging time } & \multicolumn{2}{c}{ Pod red/green colour band ratio } \\
& Correlation value & P-value & Correlation value & P-value \\
\hline Mean CPH tensile strength & 0.42 & 0.31 & 0.2 & 0.637 \\
Mean CPH compressive strength & -0.74 & 0.037 & -0.32 & 0.441 \\
Cocoa pod transverse compressive strength & -0.85 & 0.008 & -0.65 & 0.08 \\
Cocoa pod longitudinal compressive strength & -0.86 & 0.007 & -0.71 & 0.047 \\
CPH cutting force & 0.23 & 0.592 & -0.21 & 0.626 \\
Cocoa pod transverse cutting force & -0.28 & 0.495 & -0.18 & 0.675 \\
Cocoa pod longitudinal cutting force & -0.58 & 0.13 & -0.45 & 0.259 \\
CPH hardness & 0.51 & 0.195 & 0.86 & 0.006 \\
Pod red/green colour band ratio & 0.68 & 0.065 & NA & NA \\
\hline
\end{tabular}


Table 3. Results of regression analyses for compressive strength against combinations of aging time, colour and hardness

\begin{tabular}{llccc}
\hline Y-variable & \multicolumn{1}{c}{ X-variable (s) } & $\begin{array}{l}\text { Multiple R } \\
\text { (correlation } \\
\text { coefficient) }\end{array}$ & $\begin{array}{c}\text { R-squared } \\
\text { (coefficient of } \\
\text { determination) }\end{array}$ & $\begin{array}{c}\text { P-value } \\
\text { (for significance } \\
\text { level of 5\%) }\end{array}$ \\
\hline $\begin{array}{l}\text { Pod longitudinal compressive } \\
\text { strength }\end{array}$ & $\begin{array}{l}\text { Red/green colour ratio; } \\
\text { aging time }\end{array}$ & 0.88 & 0.77 & 0.026 \\
$\begin{array}{l}\text { Pod longitudinal compressive } \\
\text { strength }\end{array}$ & $\begin{array}{l}\text { Red/green colour ratio; } \\
\text { cph hardness } \\
\text { Pod longitudinal compressive } \\
\text { strength }\end{array}$ & $\begin{array}{l}\text { Red/green colour ratio; } \\
\text { cph hardness; aging time }\end{array}$ & 0.73 & 0.53 \\
\hline
\end{tabular}

The results of the regression analyses also indicate that for Equation 1: though a large proportion of the variation in compressive strength is accounted for by the variation in aging time $(74 \%)$, there are also other influential parameters. The same is true for Equation 2. Given the high level of correlation between aging time and the other two parameters, it is likely that the three properties may also be related. In keeping with this, further regression analyses were conducted to assess the level of linear correlation between the three properties and aging time. These results are presented in Table 3.

The results of the analyses confirmed the aforementioned relationship. The multiple regression analyses indicate that there is a strong linear relationship between compressive strength and a linear combination of aging time and colour ratio. It further suggests that there is an even stronger relationship when hardness penetration depth is incorporated in the linear combination. Accordingly, this gives rise to equations 3 and 4 .

Compressive Strength $=$

$-64.7(\mathrm{t})-14177.3(\mathrm{r} \mid \mathrm{g})+16352.1$

Compressive Strength $=$

$-70.5(\mathrm{t})+12202.8(\mathrm{r} \mid \mathrm{g})-$

1104.2(h) - 11655.2

Where $t$ is time in days, $\mathrm{r} \mid \mathrm{g}$ is average colour band ratio and $h$ is mean penetration depth in $\mathrm{mm}$.
In Equation 3, approximately $77 \%$ of the variation in compressive strength can be accounted for by the linear combination of parameters. In like manner, $83 \%$ is accounted for in Equation 4. This is approximately $10 \%$ more than the variation accounted for by aging time only. However, though the ANOVA analyses indicate that Equation 3 and its coefficients are statistically significant, the same is not true for Equation 4. The unreliability in the results for Equation 4 may be influenced by the underlying relationship between compressive strength and hardness. Nonetheless, given a p-value of $5.2 \%$, it is likely that a statistically significant linear combination is attainable via the modification of the coefficient values.

As a consequence of the preceding discussions, Equations 3 and 4 potentially form the basis for a useful evaluation approach. In practice, the properties of colour and hardness are easily assessed to varying levels of accuracy. Conversely, the compressive strength is not easily assessed and requires specialized equipment. However, it is a core mechanical property of the $\mathrm{CPH}$ and would significantly influence the suitability of its use for mechanical purposes. Accordingly, the foregoing equations potentially provide an easier approach for estimating and assessing the compressive strength of $\mathrm{CPH}$ and its suitability for mechanical applications. Given the results of the regression analyses, it is expected that Equation 3 would be a more accurate estimate 
of compressive strength than Equation 1. However, Equations 1 and 2 require the input of fewer parameters and consequently lead to shorter computation times. Further, Equation 2 allows for estimates of mechanical strength to be made, without even knowledge of the $\mathrm{CPH}$ age. This is potentially useful, as this information may not necessarily be available.

\section{Limitations to Application}

As mentioned previously, the foregoing results point to some key relationships between the $\mathrm{CPH}$ parameter of colour and its mechanical properties. It also points to estimates of these properties based on relationships with aging time. These relationships potentially form the basis for both the non-destructive analyses of $\mathrm{CPH}$ and for computer vision approaches to pre-processing. In both instances, the relationship between an external/visible property and internal properties are leveraged for the development of sorting or grading systems. These have the potential to lead to the development of more efficient and cost-effective systems in the pre-processing of $\mathrm{CPH}$. However, it would be noted that the relationships and equations put forward in this work, were developed for a specific variety of cocoa and with a sample size of approximately 25 to 30 cocoa pods for each test (with the exception of the colour tests, approximately 200 pods). Accordingly, a more robust statistical data set would need to be developed, as is the case with all computer-based methods of this nature, in order for the results of this work to have a wider applicability.

\section{CONCLUSIONS}

Mechanical properties of tensile and compressive strength, were both impacted by aging time. This impact was attributed to a decrease in moisture content with increasing aging time. Compressive strength was found to decrease with increasing aging time both for $\mathrm{CPH}$ samples and for whole cocoa pods. The changes in tensile strength were less evident and the parameter appeared to be less sensitive to changes in moisture content. Moreover, significant changes in both properties were noted on Day 6 and these were attributed to a possible acceleration in moisture content loss. Additionally, cocoa pod colour was found to exhibit changes that were strongly related to aging time. Further, it was found that the changes in cocoa pod colour and in compressive strength had a strong correlation, which was found to be statistically significant. Thus, a relationship between an external property of $\mathrm{CPH}$ (i.e. colour) and its mechanical strength was found to exist. Accordingly, a mathematical relationship was proposed as a means of approximating CPH strength based on aging time and pod colour. It is believed that the relationship can be utilized as a basis for more easily evaluating the strength of $\mathrm{CPH}$.

\section{ACKNOWLEDGEMENTS}

The authors of this work would like to take the time to acknowledge the support of the Cocoa Research Centre, at the University of the West Indies. Their support and assistance was critical in making this work possible. The authors would also like to specially acknowledge the European Development Fund for funding this work and the Ministry of Education, the Government of the Republic of Trinidad and Tobago, who served as the fund's administrators. Without their support, this work would not have been possible. We are indeed very grateful. 


\section{REFERENCES}

Adjin-Tetteh, M.; N. Asiedu; D. Dodoo-Arhin; A. Karam \& P.N. Amaniampong (2018). Thermochemical conversion and characterization of cocoa pod husks a potential agricultural waste from Ghana. Industrial Crops and Products, 119, 304-312.

Adzimah, S.K. \& E.K. Asiam (2010). Design of a cocoa pod splitting machine. Research Journal of Applied Sciences, Engineering and Technology, 2, 622-634.

Aroyeun, S.O.; J.O. Ogunbayo \& A.O. Olaiya (2006). Effect of modified packaging and storage time of cocoa pods on the commercial quality of cocoa beans. British Food Journal, 108(2), 141-151.

Audu, V.E.M. \& Y.W. Mamman (2013). Use of cocoa pod husk ash as admixture in concrete. International Journal of Engineering Research \& Technology, 2, 3781-3793.

Chan, S. \& W. Choo (2013). Effect of extraction conditions on the yield and chemical properties of pectin from cocoa husks. Food Chemistry, 141, 3752-3758.

Chen, H. (2016). Impacts of Huanglongbing symptom severity on fruit detachment force and mechanical properties of sweet oranges (Citrus sinensis). HortScience, 51(4), 356-361.

Chun, K.S.; S. Hussiensyah \& H. Osman (2013). Modified cocoa pod husk-filled polypropylene composites by using metacrylic acid. BioResources, 8, 32603275.

Chun, K.S.; S. Hussiensyah \& H. Osman (2013). Utilization of cocoa pod husk as filler in polypropylene biocomposites: Effect of maleated polypropylene. Journal of Thermoplastic Composite Materials, 115. DOI: 10.1177/0892705713513291.

Chun, K.S.; C.M. Yeng \& S. Hussiensyah (2016). Green coupling agent for agrowaste based thermoplastic composites. Polymer Composites, DOI 10.1002/ pc. 24228 .
Daud, Z.; A.S.M. Kassim; A.M. Aripin; H. Awang \& M.Z.M. Hatta (2013). Chemical composition and morphological of cocoa pod husks and cassava peels for pulp and paper production. Australian Journal of Basic and Applied Sciences, 7, 406-411.

Dauda, S.M.; D. Ahmad; A. Khalina \& O. Jamarei (2014). Physical and mechanical properties of kenaf stems at varying moisture contents. Agriculture and Agricultural Science Procedia, 2, 370-374.

El-Shekeil, Y.A.; S.M. Sapuan \& M.W. Algrafi (2014). Effect of fiber loading on mechanical and morphological properties of cocoa pod husk fibers reinforced thermoplastic polyurethane composites. Materials and Design, 64, 330-333.

Hinneh, M.; E. Semanhyia; D. Van de Walle; A. De Winne; D.A. Tzompa-Sosa; G.L.L. Scalone; B. De Meulenaer; K. Messens; J. Van Durme; E.O. Afoakwa; L. De Cooman \& K. Dewettinck (2018). Assessing the influence of pod storage on sugar and free amino acid profiles and the implications on some Maillard reaction related flavor volatiles in Forastero cocoa beans. Food Research International, 111, 607-620.

Igathinathane, C.; A.R. Womac \& S. Sokhansanj (2010). Corn stalk orientation effect on mechanical cutting. Biosystems Engineering, 107, 97-106.

Khanahmadi, S.; F. Yusof; A. Amid; S. Mahmod \& M.K. Mahat (2015). Optimized preparation and characterization of CLEA-lipase from cocoa pod husk. Journal of Biotechnology, 202, 153-161.

Khanahmadi, S.; F. Yusof; H.C. Ong; A. Amid $\&$ H. Shah (2016). Cocoa pod husk: A new source of CLEA-lipase for preparation of low-cost biodiesel: An optimized process. Journal of Biotechnology, 231, 95-105.

Korkmaz, O. \& U. Buyuksari (2019). Effects of moisture content on mechanical properties of micro-size Oak wood. Bioresources, 14 (4), 7655-7663. 
Leblicq, T.; S. Vanmaercke; H. Ramon \& W. Saeys (2015). Mechanical analysis of the bending behaviour of plant stems. Biosystems Engineering, 129, 87-99.

Jahangiri, M.; S.R. Hassan-Beygi; M. Aboonajmi \& M Lotfi (2016). Effects of storage duration and conditions on mechanical properties of Viola cucumber fruit under compression loading. Agricultural Engineering International: CIGR Journal, 18(2), 323-332.

Munongo, M.E.; G.E. Nkeng \& J.N. Njukeng (2017). Production and characterization of compost manure and biochar from cocoa pod husks. International Journal of Advanced Scientific Research and Management, 2, 26-31.

Murray, R.J.; S. Bachu; C. Pemberton \& R. Birch (2020). Investigation of cocoa pod husk mechanical behaviour and the impact upon specific cutting energy. The Journal of The Association of Professional Engineers of Trinidad and Tobago, 48, 22-30.

Nortey, T.Y.; D.V. Kpogo; A.L. Kpogo; A. Naazie \& E.O.K. Oddoye (2015). Cocoa pod husk is a potential feed ingredient in laying hen diets. Livestock Research for Rural Development, 27.

Ofori-Boateng, C. \& K.T. Lee (2013). The potential of using cocoa pod husks as green solid base catalysts for the transesterification of soybean oil into biodiesel: Effects of biodiesel on engine performance. Chemical Engineering Journal, 220, 395-401.

Priyangini, F.; S.G. Walde \& R. Chidambaram (2018). Extraction optimization of pectin from cocoa pod husks (Theobroma cacao L.) with ascorbic acid using response surface methodology. Carbohydrate Polymers, 202, 497-503.

Rachmat, D.; L.J. Mawarani \& D.D. Risanti (2018). Utilization of cacao pod husk (Theobroma cacao L.) as activated carbon and catalyst in biodiesel production process from waste cooking oil. IOP Conference Series: Materials Science and Engineering, 299, 012093. doi: 10.1088/1757-899X/299/1/012093.
Seifi, M.R. \& R. Alimardani (2010). The moisture content effect on some physical and mechanical properties of corn (Sc 704). Journal of Agricultural Science, 2 (4), 125-134.

Singh, K.K. \& B.S. Reddy (2006). Post-harvest physio-mechanical properties of orange peel and fruit. Journal of Food Engineering, 73 (2), 112-120.

Shodehinde, S.A. \& A. Adamson (2017). Tapping into the good use of cocoa (Theobroma cacao) pod husks: towards finding alternative sources of nutrients for animals in Nigeria. Journal of Food Technology and Preservation, 1, 42-46.

Syamsiro, M.; H. Saptoadi \& B.H. Tambunan (2011). experimental investigation on combustion of bio-pellets from Indonesian cocoa pod husk. Asian Journal of Applied Sciences, 4, 712-719.

Syamsiro, M.; H. Saptoadi; B.H. Tambunan \& N.A. Pambudi (2012). A preliminary study on use of cocoa pod husk as a renewable source of energy in Indonesia. Energy for Sustainable Development, 16, 74-77.

Ul Haque, M.M.; K. Goda; H. Ito; S. Ogoe; M. Okamot; T. Ema; K. Kagawa \& H. Nogami (2019). Melt-viscosity and mechanical behaviour of polypropylene (PP)/wood flour composites: Effect of pulverization of wood flour with and without water. Advanced Industrial and Engineering Polymer Research, 2, 42-50.

Vriesmann, L.C. \& C.L. de Oliveira Petkowicz (2017). Cacao pod husks as a source of low-methoxyl, highly acetylated pectins able to gel in acidic media. International Journal of Biological Macromolecules, 101, 146-152.

Wood, G.A.R. \& R.A. Lass (2001). Botany, types and populations. p. 11-37. In: Cocoa (Fourth Eds). Blackwell Publishing, Oxford.

$* * 0 * *$ 